\title{
Access Pricing and Asset Valuation
}

\section{Kevin Davis}

$\mathrm{A}$ ccess pricing regulation of activities such as gas and electricity transmission and distribution, transport, and telecommunications, is an important and difficult task. Owners and investors will only hold or create such assets on the expectation that regulated prices are consistent with an expected rate of return on their investment, which at least compensates for the risk incurred. Access seekers and end users naturally have concerns that access prices are not set too high, at levels that deliver excessive returns to access providers.

It is the role of regulators such as the Australian Competition and Consumer Commission (ACCC) and various State regulators to make judgements about access prices which balance, and (ideally) are seen to balance, these conflicting interests. Unfortunately, even if the process of access pricing regulation is transparent, the complexities of the issues involved means that it is often difficult for observers and participants to identify whether decisions are fair and reasonable.

One of many complications relates to the valuation of assets. Investors seek both a return over time of the financial capital invested to construct access facilities of a particular value and an appropriate rate of return on that investment. Unfortunately, there is a number of feasible ways (including market value, historical cost, or replacement cost) in which assets can be valued to derive the base on which a rate of return is calculated. Moreover, different assumptions made about asset depreciation (change in asset value), imply different paths for the return of capital over time involved in the price determination process.

The objective of this paper is to explain, for the non-specialist, certain aspects of the regulatory approach to asset valuation issues and their implications for access pricing. In doing so, the paper suggests hypotheses for potentially significant differences between the market valuation of access assets (as reflected in prices paid under privatisation) and the regulatory valuation of those assets. It also illustrates the link between regulatory assumptions about depreciation (changes in asset value over time) and the $\mathrm{X}$ factor derived in the 'CPI-X' regulatory price path for access prices. In particular, it demonstrates that the $\mathrm{X}$ factor in Australian regulation is not related to expectations of productivity increases, as often thought, but is due to regulatory assumptions about depreciation.

These results are relevant to understanding and assessing ongoing changes to the 'building block' approach used by Australian regulators to determine access prices. Although, 'in Australia, access pricing is still in its infancy' (Productivity Commission, 2001:33) there has been substantial debate and analysis of the

Kevin Davis is Commonwealth Bank Professor of Finance in the Department of Finance at the University of Melbourne. 
methods used by Australian regulators. In 1999 the ACCC released the Draft Statement of Principles for the Regulation of Transmission Revenues (DRP) (ACCC, 1999), and provided further details and implications of its preferred approach in spreadsheet models contained in the Post Tax Revenue Handbook released in October 2001 (ACCC, 2001).

As well as attempting to set benchmarks for the determination of certain key parameters in the pricing process which are applicable across all regulatory judgements (rather than being revisited on a case by case basis), the $D R P$ involved several apparently major changes in approach. These included use of a 'post-tax nominal' rather than a 'pre-tax real' rate of return in the building block approach and the use of a 'competition depreciation' approach. As will be argued below, these are more matters of style rather than substance, but are important changes in attempting to make the regulatory pricing process more transparent.

In the following section of the paper, the 'building block' approach favoured by Australian regulators is briefly outlined in order to highlight the crucial role of asset value and rate of return considerations. This is followed by a discussion of asset valuation concepts which provides a backdrop for the development of hypotheses explaining why market and regulatory asset valuations may differ. Then, some technical aspects of the changes involved in the DRP are considered, with a focus upon their implications for asset value and interpretation of regulatory determinations.

\section{Basic Model of Australian Access Regulation}

Regulators in Australia have had the advantage of observing strengths and weaknesses in pre-existing overseas approaches to access pricing - notably those of the UK and the USA. A general discussion of regulatory alternatives and comments on some aspects of the Australian approach is provided by the Treasury (1999), and the strengths and weaknesses of the UK and US approaches are discussed by Crew and Kleindorfer (1996).

It is perhaps not surprising, therefore, that the Australian approach appears to contain elements of both the 'rate of return' approach common in the USA and the 'price cap' approach that evolved in the UK. The Australian approach, as implemented by the ACCC, involves setting a price (or revenue) cap of the 'CPI-X' variety wherein prices are constrained to grow, from an initial amount, at a rate no more than the inflation rate less $\mathrm{X}$ per cent per annum over the regulatory horizon (often of five years).

To derive that price path, the Australian approach uses a 'building block' method in which the expected size of key cost components of service provision is quantified and a revenue target sufficient to meet those costs is calculated for each year of the regulatory period. In quantifying cost components, rate of return considerations enter through the inclusion of a required rate of return to investors as one of the costs which should be covered. The other key cost components are the allowance for return of capital invested over the life of the assets involved (depreciation) and for operating and maintenance costs. Forecasts for these costs 
are based on anticipated demand and expected productivity gains. Year by year variability in the revenue target can arise because of anticipated operating cost variability due to demand patterns or because of discrete jumps in depreciation amounts due to planned, lumpy, new investments. That variability gets 'smoothed out' by various value-neutral adjustments which lead to the CPI-X price (or revenue) cap path.

In line with overseas practice, the regulatory structure is intended to be an 'incentive based' one. Regulated access providers retain some part of cost savings and revenue growth from market promotion activities such that the realised rate of return can exceed that required by investors. Regulatory deliberations also include analysis of proposed investments in new capacity and resulting financing needs. For simplicity, that feature of the process is ignored in the subsequent discussion.

Alternative approaches to implementing such a model arise, inter alia, from different possible treatments of depreciation, inflation, and taxation. In early access determinations, such as the Victorian Gas Industry case of 1998, the approach had the following features. 'Current cost' depreciation was used to determine return of capital. A real pre-tax weighted average cost of capital (WACC) was used as the return on capital. The effective tax rate of the service providers was assumed equal to the statutory tax rate. In this approach, the 'real pre-tax' WACC needs to be derived from the more commonly estimated 'nominal post-tax' WACC by some adjustment to allow for inflation and tax liabilities. The 'target revenue' stream derived by use of the equation

\section{Target Revenue $=$ Operating Costs + Return of Capital + Return on Capital}

has several important features:

- taxes to be paid by the entity are allowed for implicitly through the estimated (real pre-tax) return on capital rather than as an explicit item, and

- the need for nominal cash flows to compensate for the effect of inflation is achieved through the use of a 'current cost accounting' depreciation schedule rather than through use of a 'nominal' return on capital.

In implementing this approach, significant complications arose through:

- the need to model the impact of the dividend imputation tax system on the cost of capital;

- the existence of tax depreciation allowances that were quite different to (both) regulatory and 'economic' depreciation schedules; and

- the need to develop an appropriate 'conversion formula' to convert a 'nominal post-tax' WACC to a 'real pre-tax' WACC.

The approach recommended in the $D R P$ embodies a number of significant changes reflecting concerns with the previously used method. These changes include: 
- use of a nominal post-tax return on capital concept;

- use of a 'competition depreciation' approach; and

- explicit modelling of the expected annual tax payments of the entity for explicit inclusion in the target revenue model.

These changes are not uncontroversial - although it can be shown (see Davis, 1999 or ACCC, 2001) that the different approaches are all mutually consistent (being algebraically related) and will give rise to the same outcomes, provided the correct input parameters are used in the modelling process. If incorrect parameters are used, the model can give rise to significant undesirable wealth redistribution effects affecting regulated entities, their customers, and taxpayers. In that sense, the reasons for preferring one approach over another arise from concerns over:

- accuracy of estimation of key parameters in each approach;

- transparency of the process; and

- ease of interpretation.

Since the 'true' values of the key parameters in the approaches are not observable, a concern for all participants in the process is whether particular approaches are more likely to generate better estimates of the true values or be more subject to 'gaming' behaviour and spread of misinformation.

Thus, for example, in the Victorian Gas Case, the regulators' draft determination of access prices involved a 'real pre-tax WACC' of 7 per cent, which appeared very low to many market commentators inclined to benchmark it against more familiar nominal post-tax rates of return. Following the release of the draft determinations, the price of energy stocks (particularly that of the regulated electricity business, United Energy - which had recently undertaken a public share issue) was marked down significantly. Politicians, both within Victoria and from other States began to exert public pressure. During June, the Premier of Victoria and three other state premiers sent identical letters to the State Regulator (the Office of the Regulator General) and the ACCC asserting that the proposed rate of return could adversely affect investment in the gas sector. Subsequently, the Victorian Treasurer postponed the gas privatisation program and threatened to call it off if the final access determination was seen as unsatisfactory. Eventually, the final decisions of the regulators were released in October 1998, and a real pre-tax WACC of 7.75 per cent per annum was chosen. Over the next nine months the gas businesses were sold at significant premiums to asset value.

For the 'nominal post-tax approach' favoured in the $D R P$, several advantages can be identified. These include the following. First, the explicit modelling of tax payments and franking credits in the revenue equation is more transparent, and likely to be more accurate than the alternative of incorporating tax effects in the cost of capital via use of an estimated 'effective' tax rate. Second, the approach 
avoids the problem of converting a post-tax nominal rate of return to a pre-tax real rate of return which can only be done on a case by case basis taking into account the specific tax position of the business. Third, given greater market familiarity with the former concept, use of a nominal post-tax rate of return is more easily interpreted than a real pre-tax rate of return. Fourth, as will be shown later, the use of the competition depreciation assumption should, in the absence of other distortions, align the market value of assets and the regulatory asset base valuation. Deviations of market value from regulatory valuation may then provide a clearer signal of incorrect regulatory pricing assumptions. The asset valuation approach used to determine the regulatory asset base is the Depreciated Optimised Replacement Cost (DORC) method, is one of several methods of asset valuation to which we now turn.

\section{Asset Valuation and Access Regulation}

There are a number of ways of measuring the value of an asset. They include:

- accounting measures such as historical cost (adjusted for depreciation);

- replacement cost; and

- market value.

In practice, these concepts give rise to different estimates of value for an asset, although competitive market conditions do suggest some tendency towards equality between at least two of the concepts. Specifically, if competition (or contestability) prevents the generation of abnormal profits (a return in excess of that required by suppliers of capital) market value should not exceed replacement cost (except in the short run until new entrants or expansion of capacity in response to the abnormal returns occurs). Conversely, if assets have alternative uses wherein normal profits can be earned (and can be easily transferred to those uses), market value should not fall below replacement cost.

It is also possible, in principle, if not always in practice, to adopt accounting conventions that cause accounting values to converge to either replacement value or market value. Use of 'economic depreciation' (essentially the change between reporting dates in the present value of remaining cash flows expected from the asset) would cause the accounting value to mimic market value. Use of a depreciation schedule which involves estimating the expected change between reporting dates in the replacement value of the asset (due to ageing, technological change, and price changes) would lead the accounting value to mimic replacement cost.

It is possible to think of the regulatory approach to access pricing by reference to these concepts. By attempting to provide a 'fair' rate of return to suppliers of financial capital, the regulator is targeting an outcome (in terms of efficiency of output, pricing and investment) that mimics that which would be observed under a hypothetical case of competition. If successful, market value of the assets (reflected in the market value of service providers) should be close to 
the replacement value of assets. Of course, there are many potential sources of error, not least of which is the problem caused by the fact that many regulatory assets involve 'sunk' costs, and are not able to be (easily) transferred into other uses if market value in the current activity falls below replacement cost.

It is also possible to think of some aspects of the approach to the design of regulatory models in these terms. Specifically, the adoption of certain asset valuation and depreciation practices to determine the regulatory asset base may lead to closer correspondence between that and replacement (and market) value. This is relevant in assessing the DRP. The 'competition depreciation' approach recommended in the $D R P$ attempts, in essence, to implement a depreciation schedule for the 'return of capital' component of allowable revenues that would lead to the regulatory asset base approximating the replacement value of assets. If a competitive risk-related rate of return applied to the regulatory asset base is used in access pricing determinations, the market value of the assets should equal the regulatory asset base.

Ideally, then, under the proposed regulatory framework, the market value of access providers, the regulatory asset base, and depreciated optimised replacement cost (DORC) should move closely in line. That would, if achieved, be a significant change from past experience where significant differences have been observed - prompting the question of why such differences in asset valuation may arise.

\section{Lessons from Past Experience}

The main case study available for examining the asset valuation effects of regulatory approaches used to date is that of the Victorian Gas Industry. The privatisation of the gas transmission company (Transmission Pipelines Australia), saw this company sold in May 1999 by the Victorian Government for just over \$A 1 billion, a sum more than twice the replacement value of the underlying assets. (The stapling together for sale of gas retailers and the regulated distribution companies means that individual prices for the gas distribution businesses could not be identified - although similar multiples of price paid to regulatory asset base appear to be implied). Since the regulatory regime under which the company operates should lead to future cash flows with a present value equal to (or slightly above) the replacement value of underlying assets, the gap between market value and asset replacement value presents a conundrum warranting explanation.

One possible explanation is that the 'winner's curse' has prevailed, with the successful bidder(s) simply paying too much for the company. Since similar gaps between the privatisation sale price and asset value of gas distribution companies and electricity companies (under a similar regulatory structure) appear also to have occurred, but because expected cash flows and risks are readily apparent under the regulatory regime, this seems unlikely to provide the entire (or even a large part of the) explanation. 
An alternative explanation, appealing to advocates of privatisation, is that the premium paid reflects the efficiency gains (beyond those assumed in the regulatory model) that the successful bidder believed could be extracted under private ownership. However, given the nature of the industry (operating costs constitute less than half the total costs to be covered), the magnitude of likely gains in operating efficiency cannot explain the sale-price premium. Other 'operations-side' explanations are that there may be synergies available to successful bidders who also operate other power utilities, or that the other incentive features built into the regulatory model warrant a market value in excess of asset replacement cost.

Neither of these explanations appears able to explain much of the sale-price premium, prompting two, mutually compatible, 'finance-side' hypotheses. One hypothesis is that some investors are willing to accept a rate of return lower than that used in the regulatory model. This has two effects. First, an excessive rate of return on the existing asset base is achievable for those investors. Second, future additions to the asset base would represent projects with positive net present value (NPV) - since the allowable rate of return exceeds that required. Hence, a saleprice premium would be expected. A second hypothesis is that asset values were significantly overstated, magnifying the effect of an excessive rate of return. Whether replacement of depreciated assets over time would enable this effect to be perpetuated is an open question, since the allowed return of capital would exceed the true replacement value of the assets.

Both hypotheses may contribute jointly to the explanation of a sale price premium in the privatisation process and to a gap between stock market valuation of access service providers and asset replacement values. It is worth noting that the existence of a 'back end loaded' depreciation schedule would magnify the distorting effect of both excessive asset valuations and excessive regulatory rates of return - since the excess returns would be maintained for longer.

Table 1 illustrates how use of the real depreciation approach required by the pre-tax real WACC approach used in the Gas Industry Decision implies a significant back end loading of depreciation relative to a more common straightline approach. To the extent that the complexities of the pre-tax real WACC approach obscured reality and enabled those interest groups arguing for a higher regulatory rate of return to mount a more vocal and persuasive case, any effect of resulting errors in the rate of return used would tend to be exaggerated by the back-end loading effect.

The Table demonstrates how a 'real depreciation' approach in access pricing in which depreciation is related to the inflation adjusted asset value is equivalent to 'back end loading' of depreciation. The example assumes a real interest rate of $r=5$ per cent per annum; inflation of $\pi=10$ per cent per annum; a nominal interest rate of $i=15.5$ per cent per annum consistent with the 'Fisher Effect'; an asset purchased for $\$ 100$ with a five-year life; and assumes (for simplicity) zero operating costs. Panel A demonstrates the cash flow series when the regulatory pricing model allows return of capital equal to straight-line depreciation ( $\$ 20$ per annum) plus a nominal return of 15.5 per cent of the start of period asset value. 
Panel B demonstrates the cash flow series when return of capital (depreciation) is inflation indexed (such that the amount $D_{t}^{*}$ corresponds to $\$ 20$ at date 0 prices) and where a real return of 5 per cent per annum is allowed on the inflationadjusted start of period asset value.

Panel C calculates the implied Nominal Depreciation Schedule associated with Panel B by recursively subtracting the nominal return on start of period asset value from the cash flow of Panel B to derive an implied nominal depreciation schedule. For example, in year 1 nominal return would be $\$ 100(0.155)$ which subtracted from cash flow of $\$ 27.5$ gives an implied nominal depreciation amount of $\$ 12$ and a date 1 asset value of $\$ 88$.

Table 1: The Back-End Loading of the 'Real Depreciation' Approach

\begin{tabular}{lllllll}
\hline Year & 0 & 1 & 2 & 3 & 4 & 5 \\
\hline
\end{tabular}

Panel A: Nominal Depreciation Approach — straight line depreciation

\begin{tabular}{lcccccc} 
Capital $-K_{t}$ & 100 & 80 & 60 & 40 & 20 & 0 \\
Depreciation $-D_{t}$ & & 20 & 20 & 20 & 20 & 20 \\
\cline { 2 - 6 } Cash Flow $-C_{t}$ & 35.5 & 32.4 & 29.3 & 26.2 & 23.1 \\
\hline
\end{tabular}

Panel B: Corresponding Real Depreciation Approach

\begin{tabular}{lrrrrrr}
$K_{t-1}^{*}(1+\pi)$ & & 110.0 & 96.8 & 79.9 & 58.6 & 32.2 \\
$D_{t}^{*}$ & & 22.0 & 24.2 & 26.6 & 29.3 & 32.2 \\
$K_{t}^{*}$ & 100 & 88.0 & 72.6 & 53.2 & 29.3 & 0.0 \\
\cline { 3 - 6 }$C_{t}^{*}=r K_{t-1}^{*}(1+\pi)+D_{t}^{*}$ & & 27.5 & 29.0 & 30.6 & 32.2 & 33.8 \\
\hline
\end{tabular}

Panel C: Implied Nominal Depreciation Equivalent

\begin{tabular}{lrrrrr}
$i K_{t-1}$ & 15.5 & 13.6 & 11.3 & 8.3 & 4.5 \\
$D_{t}($ implied $)=C_{t}^{*}-i K_{t-1}$ & 12.0 & 15.4 & 19.4 & 24.0 & 29.3 \\
\cline { 2 - 6 }$C_{t}^{*}$ & 27.5 & 29.0 & 30.6 & 32.2 & 33.8 \\
\cline { 2 - 6 }$K_{t}($ implied $)$ & 88.0 & 72.6 & 53.2 & 29.3 & 0.0
\end{tabular}

Assumptions: $i=15.5 \%$

$$
\begin{aligned}
& \pi=10.0 \% \\
& r=5.0 \%
\end{aligned}
$$




\section{Asset Values, 'Competition Depreciation', and Cost of Capital}

The use by the ACCC of a nominal cost of capital approach brings with it a requirement that the depreciation schedule chosen should provide for the return of a sum equal to the original cost of the asset over its life. In contrast, the real cost of capital approach built inflation compensation into the depreciation schedule rather than the cost of capital, so that the return of capital over the life of the asset was an amount equal to the real value of the original cost.

It is easily shown (drawing on the analysis of Schmalensee, 1989) that any depreciation schedule that returns 100 per cent of the original cost of the asset can be used in the building block approach adopted by the ACCC. Consider an asset with an initial cost of $K_{0}$ and a life of $N$ years. Net cash flows (revenue minus operating costs) that are based on a return of capital $D$ and a return on capital $r K$, and the NPV of each of those cash flows, are set out below in tabular form. It is assumed that the rate of return on capital allowed by regulators in the determination of cash flows is the same as that used by investors in discounting future cash flows. It should be noted that the analysis could be performed in either nominal or real terms and thus it is applicable to either a 'historical cost depreciation' (nominal rate of return)' or a 'current cost depreciation' (real rate of return) approach.

Table 2 Tabulation of Cash Flows

\begin{tabular}{|c|c|c|c|c|c|}
\hline Year & $\mathbf{0}$ & $\mathbf{1}$ & $\mathbf{2}$ & $\cdots \cdots$ & $\boldsymbol{N}$ \\
\hline Cash Flow & $-K_{0}$ & $r K_{0}+D_{1}$ & $r K_{1}+D_{2}$ & $\cdots \cdots$ & $r K_{N-1}+D_{N}$ \\
\hline $\mathrm{NPV}$ & $-K_{0}$ & $\frac{r K_{0}+D_{1}}{1+r}$ & $\frac{r K_{1}+D_{2}}{(1+r)^{2}}$ & $\cdots \cdots$ & $\frac{r K_{N-1}+D_{N}}{(1+r)^{N}}$ \\
\hline
\end{tabular}

Substituting $D_{t}=K_{t-1}-K_{t}$

\begin{tabular}{|c|c|c|c|c|c|}
\hline Year & $\mathbf{0}$ & $\mathbf{1}$ & $\mathbf{2}$ & $\cdots \cdots$ & $\boldsymbol{N}$ \\
\hline $\mathrm{NPV}$ & $-K_{0}$ & $K_{0}-\frac{K_{1}}{1+r}$ & $\frac{K_{1}}{1+r}-\frac{K_{2}}{(1+r)^{2}}$ & $\cdots \cdots$ & $\frac{K_{N-1}}{(1+r)^{N-1}}-\frac{K_{N}}{(1+r)^{N}}$ \\
\hline
\end{tabular}

Adding the NPV's of the individual cash flows to get the overall NPV we can see that provided that $K_{N}=0$ (that is, that depreciation sums to the original asset value), the overall NPV equals 0 .

It is worth reiterating that any depreciation schedule that sums to the original asset value will generate a zero NPV outcome (provided that the regulators have 
chosen the correct rate of return). At the start of the regulatory process (or when the asset is first purchased) the market value will equal the replacement cost. However, it should be noted that over the life of the asset, the regulatory asset base (given by initial value minus accumulated depreciation) could diverge from the replacement value - unless the depreciation schedule chosen happens to mimic changes in replacement cost.

The choice of 'competition depreciation' in effect aims to achieve an outcome of the regulatory asset base tracking the replacement cost of the asset over its life. At the start of the regulatory period, a projected DORC valuation for five years hence (the end of that regulatory period) is made, and depreciation is based on the difference between the current value and the projected value using a straight-line depreciation schedule. To the extent that the projected DORC is accurate, the regulatory asset base will approximate replacement cost, and, if the correct rate of return has been chosen, market value and replacement cost will be in close proximity.

It may be thought that this approach runs into problems of dealing with inflation since a DORC projection will reflect an assumed inflation rate over the regulatory period - and compensation for inflation is already built into the nominal rate of return. However, there is no conflict. Consider, for example, the case where an asset costing $\$ 100$ has a life of ten years and it is believed that its DORC value would be $\$ 50$ after five years if there were no inflation. If there were 5 per cent per annum inflation projected, the DORC value will be

$$
\$ 50(1.05)^{2}=\$ 50(1.276)=\$ 63.80 \text {. }
$$

Allowed depreciation over that five year period would be $\$ 27.20$ (rather than $\$ 50$ in the case of zero inflation). Note however, that allowed depreciation over the next five-year period would then be $\$ 63.80$ (since the DORC value at the end of 10 years will be zero). The DORC projection approach simply changes the pattern of allowable depreciation over the life of the asset when different inflation rates are assumed.

One of the merits of this approach is illustrated in Table 3. There, the case referred to in the previous paragraph is set out in a spreadsheet for the alternative scenarios of a zero expected inflation rate and a five per cent inflation rate. While in the latter scenario, the allowable depreciation over the first five year period is less than in the zero inflation case, the higher nominal return on capital (of $10.25 \%$ as given by the Fisher relationship, $i=r+\pi+r \pi$ ) exactly offsets the real cash flow consequences. The competition depreciation approach thus has the advantages of:

- preserving (approximate) equality between the regulatory asset base and the replacement cost of assets, and

- making real cash flows over the life of the asset independent of the projected rate of inflation. 
Table 3: 'Competition Depreciation' and Inflation

\begin{tabular}{|c|c|c|c|c|c|c|c|c|c|c|c|}
\hline Year & 0 & 1 & 2 & 3 & 4 & 5 & 6 & 7 & 8 & 9 & 10 \\
\hline \multicolumn{12}{|c|}{$\begin{array}{c}\text { Panel A } \\
\text { Zero Inflation Case }\end{array}$} \\
\hline DORC projection & 100 & 90 & 80 & 70 & 60 & 50 & 40 & 30 & 20 & 10 & 0 \\
\hline Depreciation $-D_{t}$ & & 10 & 10 & 10 & 10 & 10 & 10 & 10 & 10 & 10 & 10 \\
\hline Return on Capital & & 5 & 4.5 & 4 & 3.5 & 3 & 2.5 & 2 & 1.5 & 1 & 0.5 \\
\hline Cash Flow & & 15 & 14.5 & 14 & 13.5 & 13 & 12.5 & 12 & 11.5 & 11 & 10.5 \\
\hline \multicolumn{12}{|c|}{$\begin{array}{l}\text { Panel B } \\
\text { 5\% Inflation Case }\end{array}$} \\
\hline DORC projection & 100 & 94.5 & 88.2 & 81.0 & 72.9 & 63.8 & 53.6 & 42.2 & 29.5 & 15.5 & 0.0 \\
\hline Depreciation $-D_{t}$ & & 5.5 & 6.3 & 7.2 & 8.1 & 9.1 & 10.2 & 11.4 & 12.7 & 14.0 & 15.5 \\
\hline Return on Capital & & 10.3 & 9.7 & 9.0 & 8.3 & 7.5 & 6.5 & 5.5 & 4.3 & 3.0 & 1.6 \\
\hline Cash Flow & & 15.8 & 16.0 & 16.2 & 16.4 & 16.6 & 16.8 & 16.9 & 17.0 & 17.1 & 17.1 \\
\hline $\begin{array}{l}\text { Cash Flow - Real } \\
\text { Value }\end{array}$ & & 15.0 & 14.5 & 14.0 & 13.5 & 13.0 & 12.5 & 12.0 & 11.5 & 11.0 & 10.5 \\
\hline
\end{tabular}

Assumptions: $i=10.25 \%$

$$
\begin{aligned}
& \pi=5.0 \% \\
& r=5.0 \%
\end{aligned}
$$

It should be noted that the competition depreciation approach combined with $\mathrm{CPI}-\mathrm{X}$ smoothing has interesting implications for the path of revenues over the regulatory period. The smoothing process operates as follows, where it is assumed for convenience that output is constant over time such that price and revenue are perfectly correlated. In the first stage, prior to smoothing a set of target revenues $\left(c_{1}, \ldots, c_{5}\right)$ for years 1 to 5 of the current regulatory period are derived. Then, an allowable 'smoothed' set of cash flows of $\left(C_{1}, \ldots, C_{5}\right)$ are obtained as $C_{t}=C_{t-1}(1+\pi)(1-X)$ where $\pi$ is the assumed inflation rate and $\mathrm{X}$ is an adjustment factor sometimes mistakenly referred to as a 'productivity/efficiency adjustment'. The allowable cash flows are calculated by determining the $\mathrm{X}$ factor such that the present value of the series $\left(c_{1}, \ldots, c_{5}\right)$ equals the present value of $\left(C_{1}, \ldots, C_{5}\right)$, and where $c_{1}=C_{1}$. Even if different approaches to depreciation give rise to a different time path for $\left(c_{1}, \ldots, c_{5}\right)$, the CPI-X smoothing largely offsets this. There may be differences between the initial year cash flow, but these will be 
offset by differences in the calculated $X$ factor such that the present value of the allowable revenue streams are equal - provided the correct parameter values are used. However, if incorrect parameter values are used, the extent of wealth redistribution may very well be affected significantly by the approach used.

In the approach adopted by the ACCC, the CPI-X smoothing in determining the allowable revenue stream is to some extent redundant (unless there is significant year to year variations in expected operating costs). Because the allocation of depreciation over the regulatory period is based on constant real amounts per year, and is a major part of the total, the resulting nominal cash flow stream already tends to exhibit a steady growth rate. The implied $X$ factor can be calculated, but does not lead to significant adjustment to the cash flow stream. Thus for example, in the case of panel B of Table 3, the X factor can be calculated to be 3.45 per cent per annum. The close correspondence between the original cash flow stream and the smoothed cash flow stream are shown below.

\begin{tabular}{lccccc}
\multicolumn{1}{r}{ Year } & 1 & 2 & 3 & 4 & 5 \\
Original Cash Flows & 15.75 & 15.99 & 16.21 & 16.41 & 16.59 \\
Smoothed Cash Flows & 15.75 & 15.97 & 16.19 & 16.41 & 16.64
\end{tabular}

It is worth asking what interpretation can be placed on the $\mathrm{X}$ adjustment factor. It can be shown that the $\mathrm{X}$ factor will be zero if the allocation of depreciation over the regulatory horizon is based on a 'real annuity approach'. In such a case, the annual allocation of depreciation is back-end loaded to an amount that means that the real cash flows generated from the model are constant over the period. Since in that case, target nominal cash flows are related by $c_{t}=c_{t-1}(1+\pi)$, the $\mathrm{X}$ factor used to derive allowable cash flows $\left(C_{l}, \ldots, C_{5}\right)$ will clearly be zero. If the depreciation schedule is more 'back loaded' than the real annuity schedule, the $\mathrm{X}$ factor derived will be negative. This reflects the fact that the initial period cash flow is less than for the real annuity case and that a steeper increase in future period cash flows is necessary to achieve the same NPV over the regulatory period. Conversely, if the depreciation schedule is more 'front loaded' than the real annuity schedule (such as in the case of a straight line allocation), the $\mathrm{X}$ factor will be positive. Thus, the $\mathrm{X}$ adjustment factor has nothing to do with efficiency or productivity issues, but is an immediate consequence of the choice of depreciation schedule over the regulatory period. The approach adopted by the ACCC of constant real allocations of depreciation over the regulatory period means that a positive $X$ factor can be expected. Simulations suggest that a figure in the region of 3 per cent per annum can be expected, with higher values for higher real rates of return. The $\mathrm{X}$ factor is unaffected by the assumed rate of inflation. 


\section{Conclusion}

The 'competition depreciation' approach advocated by the ACCC, together with the 'building block' approach should, if regulatory determination of initial asset values and required rates of return are correct, lead to close correspondence between the regulatory asset base, the replacement cost of assets, and the market value of those assets.

This is a desirable feature of the approach, and is enhanced by the choice of a post-tax nominal rate of return approach to the determination of revenue streams. Such an approach is more transparent than the real pre-tax WACC approach previously adopted, so that causes of discrepancies between those asset valuation concepts are, hopefully, more likely to be readily identified and corrected.

\section{References}

ACCC (1999), Draft Statement of Principles for the Regulation of Electricity Transmission Revenues, Australian Competition and Consumer Commission, 27 May, http://www.accc.gov.au/electric/sridiisseme/sridissemi.htm.

ACCC (2001), Post Tax Revenue Handbook, Australian Competition and Consumer Commission, http://www.accc.gov.au/gas/fs-gas.htm.

Crew, M. and P. Kleindorfer (1996), 'Incentive Regulation in the United Kingdom and the United States: Some Lessons', Journal of Regulatory Economics 9:211-25.

Davis, K. (1999), 'The Design of Regulatory Pricing Models for Access Arrangements: Inflation, Tax and Depreciation Considerations',

http://accfinnt3.ecom.unimelb.edu.au/finance/staff/kevintd/papers/RegulatoryDepreciation Schedules.pdf.

Productivity Commission (2001), Review of the National Access Regime: Position Paper, http://www.pc.gov.au/inquiry/access/positionpaper/.

Schmalensee, R. (1989), 'An Expository Note on Depreciation and Profitability Under Rate-of-Return Regulation', Journal of Regulatory Economics 1:293-298.

Treasury (1999), 'Price Regulation of Utilities', Treasury Economic Roundup Summer:57-69.

Based on a paper originally prepared for an Australian Competition and Consumer Commission Asset Valuation Forum held in Melbourne on 16/6/00. I am grateful to the Editor and anonymous referees for valuable comments on an earlier draft. 